\title{
Elastic Recoil Detection Analysis of Hydrogen content in diamonds
}

\author{
HÉLÈNE BUREAU ${ }^{1}$, HICHAM KHODJA ${ }^{2}$, IMÈNE \\ ESTÈVE $^{1}$, MATTHIEU CHARRONDIÈRE-LEWIS ${ }^{1}$, ELOISE \\ GAILLOU $^{3}$, JEAN-CLAUDE BOULLIARD ${ }^{1}$, KEEVIN \\ BENEUT $^{1}$, PIERRE CARTIGNY ${ }^{4}$ AND SYLVIE \\ DEMOUCHY $^{5}$ \\ ${ }^{1}$ IMPMC \\ ${ }^{2} \mathrm{NIMBE} / \mathrm{LEEL}$ \\ ${ }^{3}$ Musée de Minéralogie MINES ParisTech \\ ${ }^{4}$ IPGP \\ ${ }^{5}$ Geosciences Montpellier \\ Presenting Author: helene.bureau@upmc.fr
}

Hydrogen or water absolute concentrations remain difficult to measure in nominally anhydrous minerals but it can now be accurately determined using ERDA (Elastic Recoil Detection Analysis using a nuclear microprobe) technique. Since over a decade this method has been shown to be reliable for the absolute quantification of water in geologic materials.

These last years ERDA was successfully used to: (a) determine the partitioning of hydrogen between metallic phases and silicates in equilibrium with each other [1, 2], aiming at quantifying the hydrogen content in the Earth's core; (b) quantify water incorporation in minerals from the Earth's mantle transition zone and to calibrate absorption coefficients for FTIR analyses of ringwoodites and wadsleyites [3, 4]; (c) calibrate water analysis in Focused Ion Beam (FIB) sections of NAMs with a nanoSIMS [5].

Another very challenging goal is the examination of hydrogen content in diamonds.

Diamonds are unique witnesses of the deep Earth interior and history, but up to now very little has been undertaken on $\mathrm{H}$ in diamonds, and in their inclusions. In diamonds, $\mathrm{H}$ leads to a series of infrared (IR) active defects (primarily C-H at $3107 \mathrm{~cm}^{-1}$, [6]) for which the respective absorption coefficient has never been determined, leaving no room for an absolute determination of $\mathrm{H}$ concentration. In addition, all $\mathrm{H}$ may not be IR-active $\mathrm{H}$ as suggested by pioneer ERDA measurements [7].

We will present accurate ERDA determinations of hydrogen contents in natural diamonds, that we will compare with their FTIR spectra. We will discuss how these results can bring constraints on the deep Earth hydrogen (water) cycle.

[1] V. Clesi et al. (2018) planets. Sci. Adv. 4, e1701876.

[2] V. Malavergne, et al. (2018), Icarus, 321, 473-485.

[3] N. Bolfan-Casanova et al. (2018) Front. Earth Sci., doi: 10.3389/feart.2018.00075.

[4] W. R. Panero et al. (2020) Geochemistry, Geophysics, Geosystems. 21, e2019GC008712. [5] D. Lévy et al. (2019) Analytical Chemistry doi: 10.1021/acs.analchem.9b03134.

[6] E. Fritsch, et al. (2007) New diamond and Frontier Carbon Technology. 17/2, 63-89.

[7] R.J. Sweeney, et al. (1999) NIM B 158, 582-587. 